\title{
Correction to: Ultrasound thermal monitoring with an external ultrasound source for customized bipolar RF ablation shapes
}

\author{
Younsu Kim ${ }^{1} \cdot$ Chloé Audigier $^{1} \cdot$ Jens Ziegle $^{2} \cdot$ Michael Friebe $^{2} \cdot$ Emad M. Boctor $^{1}$
}

Published online: 1 June 2018

(c) CARS 2018

\section{Correction to: International Journal of Computer Assisted Radiology and Surgery https://doi.org/10.1007/s11548-018-1744-4}

The original article has been published without article note. The article note should be:

Younsu Kim and Chloé Audigier are joint first authors, having contributed equally to this work.

Also there is a mistake in co-author's (Chloé Audigier) email address, it should be caudigi1@jhmi.edu.

The original article can be found online at https://doi.org/10.1007/ s11548-018-1744-4.

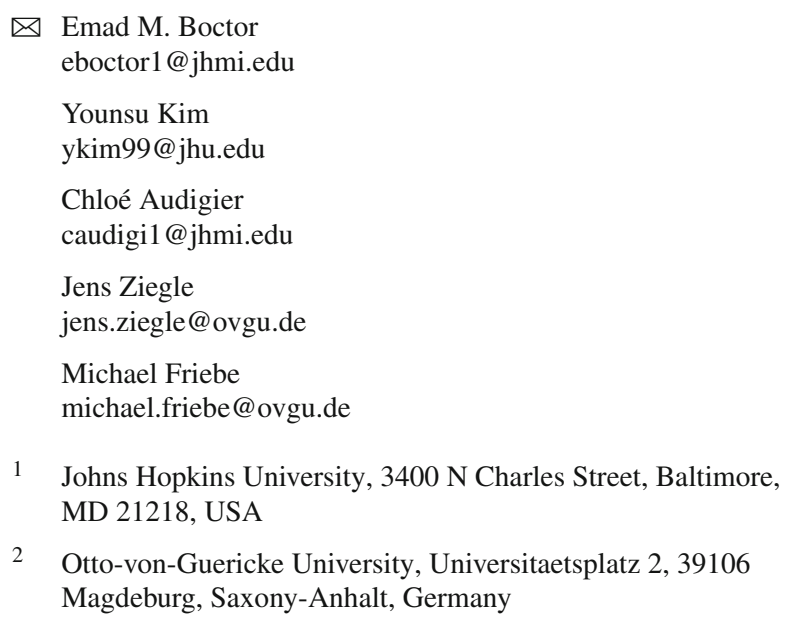

2 Otto-von-Guericke University, Universitaetsplatz 2, 39106 Magdeburg, Saxony-Anhalt, Germany 